\title{
Extracting the effective bandgap of heterojunctions using Esaki diode I-V measurements
}

Quentin Smets, Anne S. Verhulst, Salim El Kazzi, Devin Verreck, Olivier Richard, Hugo Bender, Nadine Collaert, Anda Mocuta, Aaron Thean, and Marc M. Heyns

Citation: Appl. Phys. Lett. 107, 072101 (2015);

View online: https://doi.org/10.1063/1.4928761

View Table of Contents: http://aip.scitation.org/toc/apl/107/7

Published by the American Institute of Physics

\section{Articles you may be interested in}

InGaAs tunnel FET with sub-nanometer EOT and sub-60 mV/dec sub-threshold swing at room temperature Applied Physics Letters 109, 243502 (2016); 10.1063/1.4971830

Band parameters for III-V compound semiconductors and their alloys Journal of Applied Physics 89, 5815 (2001); 10.1063/1.1368156

InGaAs tunnel diodes for the calibration of semi-classical and quantum mechanical band-to-band tunneling models

Journal of Applied Physics 115, 184503 (2014); 10.1063/1.4875535

A model determining optimal doping concentration and material's band gap of tunnel field-effect transistors Applied Physics Letters 100, 193509 (2012); 10.1063/1.4714544

Assessment of field-induced quantum confinement in heterogate germanium electron-hole bilayer tunnel fieldeffect transistor

Applied Physics Letters 105, 082108 (2014); 10.1063/1.4894088

Figure of merit for and identification of sub-60 mV/decade devices

Applied Physics Letters 102, 013510 (2013); 10.1063/1.4773521

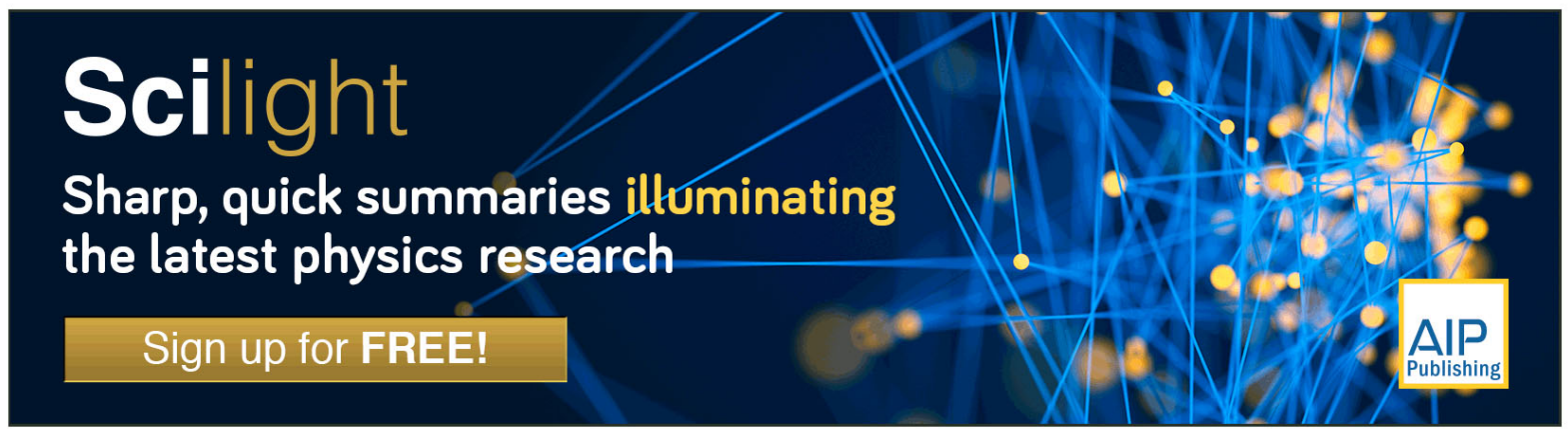




\title{
Extracting the effective bandgap of heterojunctions using Esaki diode I-V measurements
}

\author{
Quentin Smets, ${ }^{1,2, a)}$ Anne S. Verhulst, ${ }^{1}$ Salim El Kazzi, ${ }^{1}$ Devin Verreck, ${ }^{1,2}$ Olivier Richard, ${ }^{1}$ \\ Hugo Bender, ${ }^{1}$ Nadine Collaert, ${ }^{1}$ Anda Mocuta, ${ }^{1}$ Aaron Thean, ${ }^{1}$ and Marc M. Heyns ${ }^{1,2}$ \\ ${ }^{1}$ Imec, Kapeldreef 75, 3001 Heverlee, Belgium \\ ${ }^{2}$ KULeuven, 3000 Leuven, Belgium
}

(Received 16 June 2015; accepted 7 August 2015; published online 17 August 2015)

\begin{abstract}
The effective bandgap is a crucial design parameter of heterojunction tunneling field-effect transistors. In this letter, we demonstrate a method to measure the effective bandgap directly from the band-to-band tunneling current of a heterojunction Esaki diode, of which we only require knowledge of the electrostatic potential profile. The method is based on a characteristic exponentially increasing current with forward bias, caused by sharp energy filtering at cryogenic temperature. We apply this method experimentally to a $\mathrm{n}+\mathrm{In}_{0.53} \mathrm{Ga}_{0.47} \mathrm{As} / \mathrm{pGaAs}_{0.5} \mathrm{Sb}_{0.5}$ Esaki diode and define requirements to apply it to other heterojunctions. (C) 2015 AIP Publishing LLC.
\end{abstract}

[http://dx.doi.org/10.1063/1.4928761]

The effective bandgap ( $E_{g, \text { eff }}$, inset of Fig. 1) of heterojunctions is a crucial design parameter for Resonant Interband Tunneling Diodes (RITD) for high speed analog applications ${ }^{1}$ and Tunneling Field-Effect Transistors (TFET) for ultra low power logic. ${ }^{2} E_{g, e f f}$ is usually determined from the electron affinities and bandgaps of the bulk materials, ${ }^{3}$ or using optical measurements. ${ }^{4,5}$ However, there is significant uncertainty on $E_{g, e f f}$, especially for the heterostructure $\operatorname{In}_{0.53} \mathrm{Ga}_{0.47} \mathrm{As} /$ $\mathrm{GaAs}_{0.5} \mathrm{Sb}_{0.5}$ (InGaAs/GaAsSb, Fig. 1), which makes the prediction of TFET performance difficult. ${ }^{6}$ The lattice-matched $\mathrm{In}_{\mathrm{x}} \mathrm{Ga}_{1-\mathrm{x}} \mathrm{As} / \mathrm{GaAs}_{1-\mathrm{y}} \mathrm{Sb}_{\mathrm{y}}$ heterojunction system is promising for TFET $^{3,7-13}$ due to its tunable $E_{\mathrm{g}, \text { eff }}$ (Fig. 1). In this letter, we present and experimentally demonstrate a method to measure $\mathrm{E}_{\mathrm{g}, \mathrm{eff}}$ directly from the Band-To-Band Tunneling current density $\left(\mathrm{J}_{\mathrm{BTBT}}\right)$ of a InGaAs/GaAsSb Esaki diode.

The method requires a $\mathrm{p}+/ \mathrm{n}$ or $\mathrm{p} / \mathrm{n}+$ Esaki diode (Figs. 2(a) and 2(c)) with a staggered (type II) or straddled (type I) band alignment, of which the highly doped region is highly degenerate and the lowly doped region is lowly degenerate or non-degenerate. Semiclassical ${ }^{14}$ (Figs. 2(b) and 2(d)) and Quantum Mechanical $^{15}$ (QM) simulations at cryogenic temperature show a nearly exponentially increasing BTBT current with more negative reverse bias $0>V_{n p}>V_{c}$, which is unusual for $\mathrm{p}+/ \mathrm{n}+$ Esaki diodes. $\mathrm{V}_{\mathrm{c}}$ is the voltage where BTBT no longer increases exponentially and can easily be recognized visually. It will be theoretically shown that $E_{g, \text { eff }}$ can be extracted from $\mathrm{V}_{\mathrm{c}}$ without requiring knowledge of the bandgaps or tunneling rates.

In order to intuitively understand the origin of the exponentially increasing current, we theoretically derive the approximate $\mathrm{I}-\mathrm{V}$ relation for $\mathrm{p} / \mathrm{n}+$ diodes (Fig. 2(a)). A similar derivation can be made for $\mathrm{p}+/ \mathrm{n}$ diodes (Fig. 2(c)). The exponential current originates from a sharp energy filtering mechanism. Tunneling occurs dominantly at $\mathrm{E}=\mathrm{E}_{\mathrm{fp}}$, along a path which starts at the hetero-interface and ends in the lowly p-type doped material (Fig. 2(a)). Tunneling at the highest energy levels $\left(E>E_{f p}\right)$ is suppressed because these

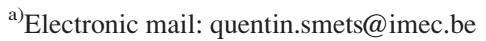

tunnel paths are longer (Fig. 3(a)). At cryogenic temperature, tunneling at $\mathrm{E}<\mathrm{E}_{\mathrm{fp}}$ is also suppressed due to a reduced amount of empty states $1-f_{F D p}(E)$, with $f_{F D p}(E)$ the FermiDirac occupation in the p-type region. This causes a peak in tunneling near $\mathrm{E}_{\mathrm{fp}}$. The BTBT current can therefore be described by considering tunneling only at this energy and using the Wentzel-Kramer-Brillouin (WKB) approximation

$$
\mathrm{J}_{\mathrm{BTBT}} \propto \exp \left(-2 \int_{0}^{\mathrm{L}} \kappa d x\right),
$$

where $\kappa$ is the magnitude of the imaginary wavevector $\mathrm{k}$ along the tunnel path in the forbidden gap $^{16}$ and $\mathrm{L}$ is the length of the tunnel path. Due to the quadratic band bending in GaAsSb (Fig. 4(a)), the shape of $\kappa(\mathrm{x})$ in GaAsSb remains unchanged with more negative $\mathrm{V}_{\mathrm{np}}$, and only the limits of the integration change. For $0>\mathrm{V}_{\mathrm{np}}>\mathrm{V}_{\mathrm{c}}$, the value of $\kappa(x=0)$ is nearly constant because the tunnel path starts close to midgap. We can locally approximate that $\mathrm{L}$ decreases linearly with $-\mathrm{V}_{\mathrm{np}}$ down to $\mathrm{V}_{\mathrm{c}}$ (Fig. 4(c)). This causes $\mathrm{J}_{\mathrm{BTBT}}$ to increase nearly exponentially (Fig. 4(b)). When $\mathrm{V}_{\mathrm{np}}<\mathrm{V}_{\mathrm{c}}$, the tunnel path extends into InGaAs and the current no longer increases exponentially, which allows the visual extraction of $\mathrm{V}_{\mathrm{c}}$ from the I-V curve. More rigorous simulations with a fully QM 15band $\mathrm{k} \cdot \mathrm{p}$ solver $^{15}$ (not shown) confirm the same trends in the I-V curve. Contrary to the WKB approximation, the QM simulations do not neglect wavefunction reflections due to the discontinuity in $\kappa(x)$ at the heterointerface. ${ }^{17,18}$

We can easily extract $E_{g, e f f}$ from $V_{c}$, because at this bias condition, $\mathrm{E}_{\mathrm{c}}$ of InGaAs at the hetero-interface is equal to $\mathrm{E}_{\mathrm{fp}}$ (Fig. 4(a)). Therefore, we obtain the relation

$$
E_{\mathrm{g}, \mathrm{eff}}=q\left(\Delta \Psi_{n}+\Delta \Psi_{p}-\mathrm{V}_{\mathrm{c}}\right)-\xi_{n}-\xi_{p},
$$

where $q$ is the elementary charge, $\Delta \Psi_{n}, \Delta \Psi_{p}$ are the band bending of the $\mathrm{n}$ and $\mathrm{p}$ regions at $\mathrm{V}_{\mathrm{np}}=\mathrm{V}_{\mathrm{c}}$ (Fig. 4(a)), and the degeneracies are $\xi_{n}=\mathrm{E}_{\mathrm{fn}}-\mathrm{E}_{\mathrm{c}, \mathrm{n} \text {,bulk }}$ and $\xi_{p}=\mathrm{E}_{\mathrm{v}, \mathrm{p} \text {,bulk }}-\mathrm{E}_{\mathrm{fp}}$ or zero if non-degenerate. In order to be valid for staggered and straddled heterojunctions, we define the effective 


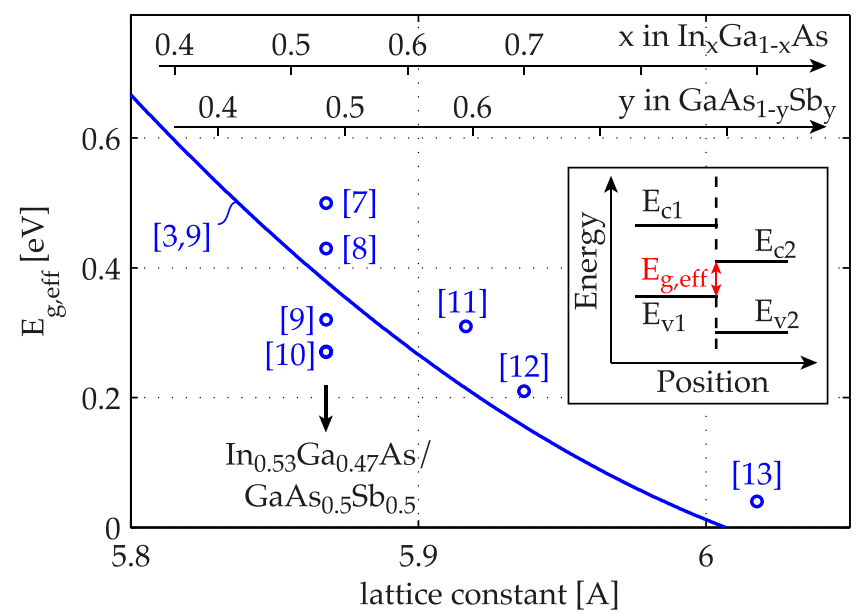

FIG. 1. Many lattice matched $\operatorname{In}_{\mathrm{x}} \mathrm{Ga}_{1-\mathrm{x}} \mathrm{As} / \mathrm{GaAs}_{1-\mathrm{y}} \mathrm{Sb}_{\mathrm{y}}$ heterojunction TFETs have been demonstrated in literature, but there is significant uncertainty on the reported $E_{g, \text { eff }}$. The full line is calculated from electron affinities and bandgaps of the bulk materials. ${ }^{3,9}$

bandgap at the hetero-interface as $\mathrm{E}_{\mathrm{g}, \mathrm{eff}}=\mathrm{E}_{\mathrm{c}, \mathrm{n}}-\mathrm{E}_{\mathrm{v}, \mathrm{p}}$ with $E_{c, n}$ the n-type region conduction band edge and $E_{v, p}$ the p-type region valence band edge, both taken at the heterointerface (Figs. 2(a) and 2(c)).

Four requirements are identified to obtain nearly exponentially increasing current in $\mathrm{p} / \mathrm{n}+$ Esaki diodes. First, the temperature must be sufficiently low (Fig. 3(b)). Simulations show the required temperature decreases with higher p-type dopant concentration, lower $\mathrm{E}_{\mathrm{g}, \text { eff }}$, and higher degeneracy $\xi_{p}$. Experimentally this required temperature can be found easily
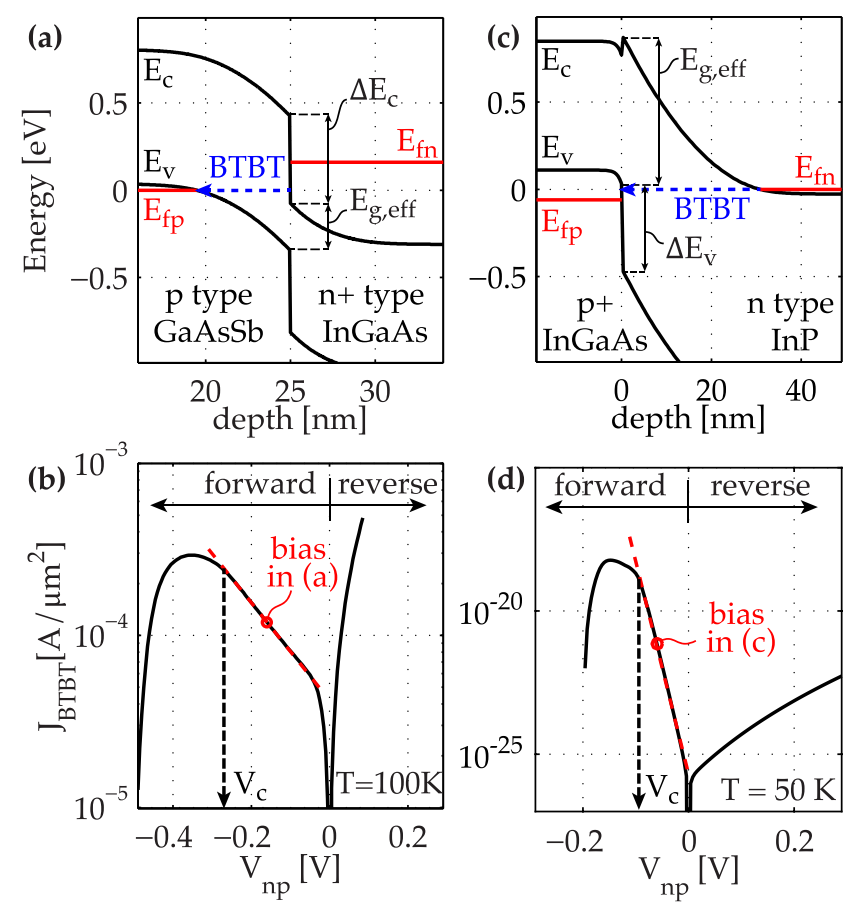

FIG. 2. (a) The band diagram of a forward biased $p / n+$ Esaki diode with staggered alignment shows tunneling from the heterointerface to the lowly doped region. $\mathrm{E}_{\mathrm{c}}, \mathrm{E}_{\mathrm{v}}$ are conduction and valence band edges and $\mathrm{E}_{\mathrm{fn}}, \mathrm{E}_{\mathrm{fp}}$ are the quasi Fermi energy levels. (b) The corresponding simulation ${ }^{14}$ shows $\mathrm{J}_{\mathrm{BTBT}}$ increases exponentially with forward bias at sufficiently low temperature. (c) and (d) Similar behavior for a $\mathrm{p}+/ \mathrm{n}$ heterojunction with straddled alignment.
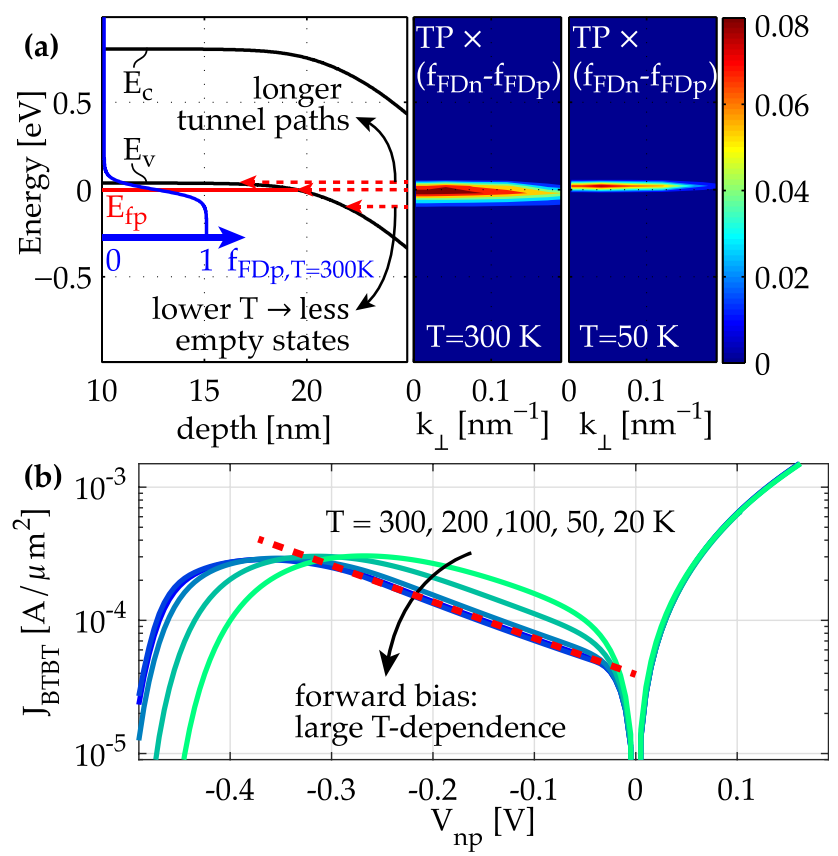

FIG. 3. (a) The dashed arrows in the GaAsSb band diagram show suppressed tunneling at $\mathrm{E}>\mathrm{E}_{\mathrm{fp}}$ and $\mathrm{E}<\mathrm{E}_{\mathrm{fp}}$. The Transmission Probability (TP) weighted with Fermi-Dirac shows a peak in tunneling near $\mathrm{E}_{\mathrm{fp}}$ at $\mathrm{T}=50 \mathrm{~K}$. The TP is calculated with a 15-band $\mathrm{k} \cdot \mathrm{p}$ solver ${ }^{15}$ and $\mathrm{k}_{\perp}$ is the wavevector perpendicular to the tunneling direction. (b) Simulations ${ }^{14}$ show that at small forward bias, $\mathrm{J}_{\mathrm{BTBT}}$ is temperature dependent for $\mathrm{T}>100 \mathrm{~K}$ and exponential for $\mathrm{T}<100 \mathrm{~K}$.

by performing $\mathrm{I}-\mathrm{V}$ measurements and lowering the temperature until the I-V no longer changes. Second, intermixing of both semiconductors near the heterointerface must be sufficiently low. Simulations show that the current is no longer exponential if the intermixing region is larger than $1 \mathrm{~nm}$. Third, the degeneracy $\xi_{\mathrm{n}}$ must be larger than the band bending of the $\mathrm{n}+$ region $\left(\Delta \Psi_{n}\right.$ in Fig. $\left.4(\mathrm{a})\right)$ at $\mathrm{V}_{\mathrm{np}}=0$. This is easily achieved in $\mathrm{n}+\mathrm{InGaAs}$ due to its low conduction band density of states, but not in $\mathrm{n}+$ silicon. Finally, the conduction band offset at the hetero-interface $\left(\Delta \mathrm{E}_{\mathrm{c}}\right.$ in Fig. 2(a)) must be positive and sufficiently large $\left(q \Delta \mathrm{E}_{\mathrm{c}}>\xi_{\mathrm{n}}-q \Delta \Psi_{n}\right)$ such that the tunnel path starts at the heterointerface at $\mathrm{V}_{\mathrm{np}}=0$. This is the case for $\mathrm{n}+\mathrm{InGaAs} / \mathrm{pGaAsSb}$ but not for $\mathrm{n}+\mathrm{InGaAs} / \mathrm{pInP}$. Furthermore, simulations show that the method remains valid in the limit of a near-broken bandgap heterojunction with $\mathrm{E}_{\mathrm{g}, \mathrm{eff}}=0 \mathrm{eV}$.

We experimentally verify our prediction of exponential BTBT current in a forward biased diode. ${ }^{6}$ An InGaAs/ $\mathrm{GaAsSb}$ heterojunction is grown on a lattice matched InP substrate with Molecular Beam Epitaxy (MBE) as described in Ref. 20. The active dopant concentrations $\mathrm{n}=3.3$ $\times 19^{19} \mathrm{~cm}^{-3}$ and $\mathrm{p}=1.1 \times 19^{19} \mathrm{~cm}^{-3}$ are obtained with Hall measurements and satisfy the previously mentioned requirements for exponential BTBT current. Transmission Electron Microscopy (HR-HAADF-STEM, Fig. 5) analysis confirms a sharp hetero-interface with less than $1 \mathrm{~nm}$ of intermixing. Diodes with junction areas $\mathrm{A}_{\mathrm{j}}=0.01-2 \mu \mathrm{m}^{2}$ are fabricated according to the process flow in Ref. 21. We measure the diode I-V characteristics with an Agilent $4156 \mathrm{C}$ parameter analyzer. Perimeter effects are negligible, since $\mathrm{I}_{\mathrm{BTBT}}$ scales with $A_{j}$ in reverse (inset of Fig. 6) and forward bias, but only after correction for series resistance $R_{S}$ according to the 

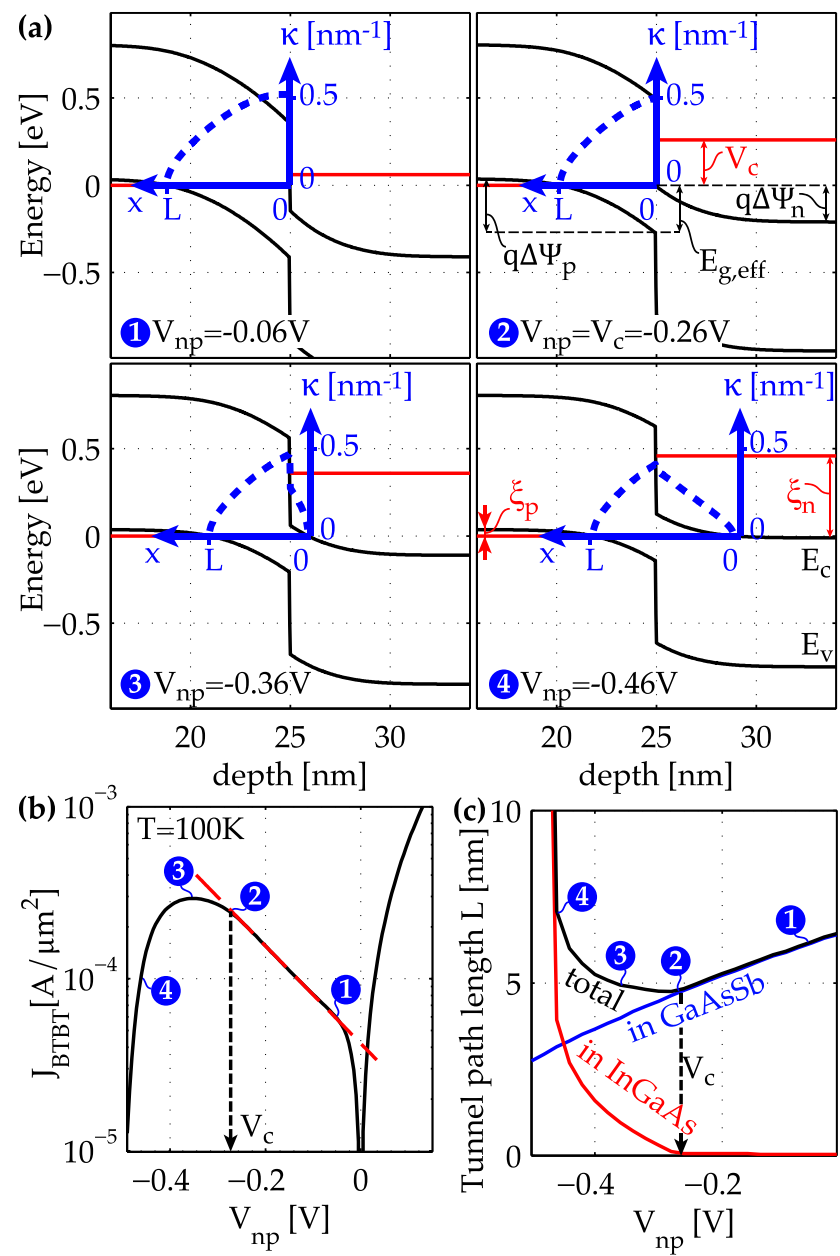

FIG. 4. (a) and (c) The tunnel path at $\mathrm{E}=\mathrm{E}_{\mathrm{fp}}$ is located entirely in GaAsSb for $0>V_{n p}>V_{c}$, and extends to InGaAs for $V_{n p}<V_{c}$. $\kappa$ is calculated using the Kane 2-band dispersion relation. ${ }^{19}$ (b) The current no longer increases exponentially when $\mathrm{V}_{\mathrm{np}}<\mathrm{V}_{\mathrm{c}}$.

procedure described in Ref. 20. The measured $\mathrm{V}_{\mathrm{c}}$ can be severely impacted by a high $\mathrm{R}_{\mathrm{s}}$ if the $\mathrm{I}-\mathrm{V}$ curves are not corrected. ${ }^{6}$ While the peak voltage of diodes with $\mathrm{A}_{\mathrm{j}}=0.04 \mu \mathrm{m}^{2}$ shifts by only $0.02 \mathrm{~V}$, diodes with $\mathrm{A}_{\mathrm{j}}=2 \mu \mathrm{m}^{2}$ carry more current and the peak voltage is shifted by $0.1 \mathrm{~V}$ when correcting for $R_{s}=350 \Omega$. When the temperature is lowered, we observe a decrease of BTBT in forward bias, and the I-V becomes more exponential (Fig. 6) as predicted by simulations (Fig. 3(b)). The exponential current also confirms that the intermixing region at the heterojunction is smaller than $1 \mathrm{~nm}$. At $\mathrm{T}=78 \mathrm{~K}$, we extract $\mathrm{V}_{\mathrm{c}}=-0.27 \mathrm{~V}$ from 4 diodes with different areas.

In order to extract $\mathrm{E}_{\mathrm{g}, \text { eff }}$ from $\mathrm{V}_{\mathrm{c}}$ using Eq. (2), we calculate the degeneracies $\xi_{n, p}$ and band bending $\Delta \Psi_{n, p}$ at $\mathrm{V}_{\mathrm{c}}$ using the measured active dopant concentrations and Sentaurus Device. ${ }^{14}$ We use Fermi-Dirac statistics and the effective mass approximation for the light hole, heavy hole, and conduction bands with a nonparabolicity correction in the $\Gamma, L$, and $X$ valleys. ${ }^{3,9,22}$ We assume dopant-dependent bandgap narrowing (dopant-BGN) does not increase the degeneracy, and we obtain $\xi_{\mathrm{n}}=0.47 \mathrm{eV}$ and $\xi_{\mathrm{p}}=0.04 \mathrm{eV}$ at $\mathrm{T}=78 \mathrm{~K}$. We obtain a match between simulated and measured $\mathrm{V}_{\mathrm{c}}=-0.27 \mathrm{~V}$ at $\mathrm{T}=78 \mathrm{~K}$ with $\mathrm{E}_{\mathrm{g}, \mathrm{eff}}=0.27 \mathrm{eV}$. We then extrapolate this result to $\mathrm{T}=300 \mathrm{~K}$ using literature data
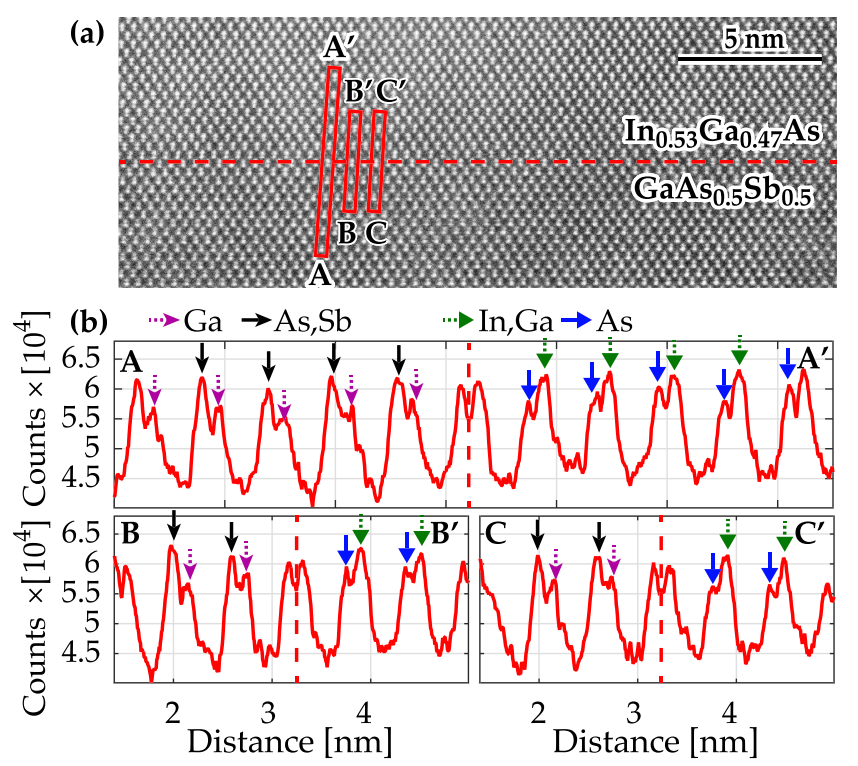

FIG. 5. (a) HR-HAADF-STEM analysis and (b) the intensity traces along A-A', B-B', and C-C' show a locally smooth and sharply defined heterointerface with an intermixing region smaller than $1 \mathrm{~nm}$ and no visible defects.

on temperature dependent bandgap narrowing ${ }^{23,24}$ and obtain $\mathrm{E}_{\mathrm{g}, \mathrm{eff}}=0.21 \mathrm{eV}$. Currently, we cannot quantitatively compare the full measured and simulated $\mathrm{I}-\mathrm{V}$, since this requires a profound understanding of dopant-BGN on BTBT rates.

We assess the sensitivity of $\mathrm{E}_{\mathrm{g} \text {,eff }}$ to the different input parameters in Eq. (2) using semiclassical simulations. If an error $\Delta \mathrm{V}_{\mathrm{c}}= \pm 20 \mathrm{mV}$ is made during the experimental extraction in Fig. 6, this results in an error $\Delta \mathrm{E}_{\mathrm{g} \text {,eff }}$ $= \pm 45 \mathrm{meV}$. If an error is made on $\xi_{\mathrm{n}}, \xi_{\mathrm{p}}$ due to a possibly inaccurate density of states model, $\Delta \xi_{\mathrm{p}}= \pm 20 \mathrm{meV}$ results in an error $\Delta \mathrm{E}_{\mathrm{g}, \text { eff }}=\mp 20 \mathrm{meV}$, and $\Delta \xi_{\mathrm{n}}= \pm 20 \mathrm{meV}$ results in $\Delta \mathrm{E}_{\mathrm{g}, \text { eff }}= \pm 11 \mathrm{meV}$.

Even when considering these possible error bars, our obtained $E_{\mathrm{g} \text {,eff }}$ is lower than other literature values for the undoped $\mathrm{In}_{0.53} \mathrm{Ga}_{0.47} \mathrm{As} / \mathrm{GaAs}_{0.5} \mathrm{Sb}_{0.5}$ heterojunction ${ }^{7-10}$ $\left(E_{g, \text { eff }}=0.27-0.5 \mathrm{eV}\right.$, see Fig. 1). We identify three possible explanations for this discrepancy: First, dopant-BGN could

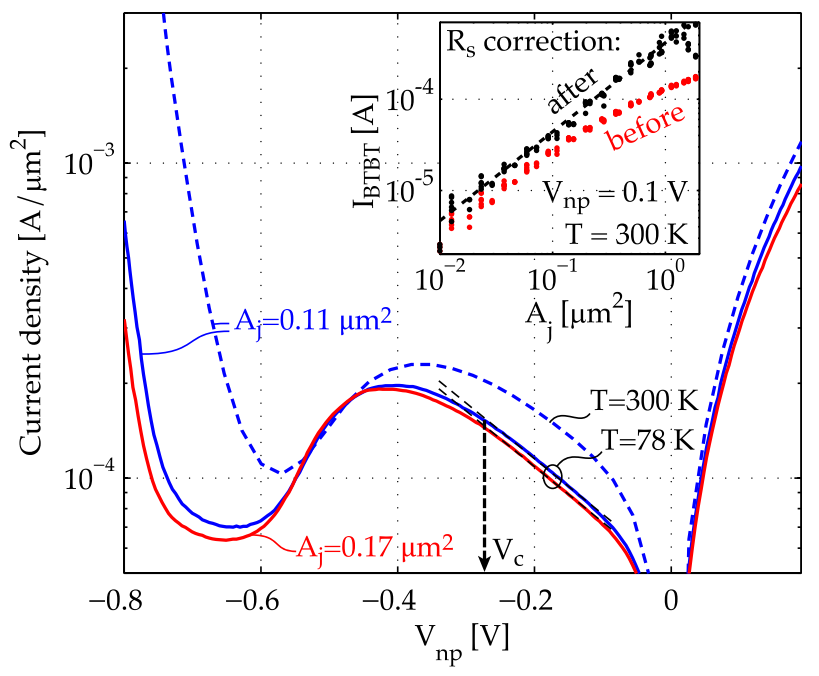

FIG. 6. The measured I-V curves become more exponential at $\mathrm{T}=78 \mathrm{~K}$. We extract $\mathrm{V}_{\mathrm{c}}=-0.27 \mathrm{~V}$ from 2 diodes with different areas. The inset shows $\mathrm{I}_{\mathrm{BTBT}}$ scales with the junction area, but only after correcting for series resistance. 
increase $\xi_{n}$ and $\xi_{p}$ and therefore also $\Delta \Psi_{n, p}$. This would result in a underestimated $E_{g, e f f}$ for the same measured $V_{c}$ $=-0.27 \mathrm{~V}$. Our obtained value $\mathrm{E}_{\mathrm{g}, \mathrm{eff}}=0.21 \mathrm{eV}$ is therefore a lower limit.

Second, heavy doping could shift $\Delta \mathrm{E}_{\mathrm{c}}$ and $\Delta \mathrm{E}_{\mathrm{v}}$ and decrease $E_{g, e f f}{ }^{25}$ Further extrapolation to an undoped heterojunction using literature values of Jain Roulston dopant-BGN ${ }^{25,26}$ results in $\mathrm{E}_{\mathrm{g}, \mathrm{eff}}=0.39 \mathrm{eV}$, which brings our measured value in the range found in literature.

The third possibility is a fixed interface charge affecting the band bending, as reported in Ref. 5 for a $\operatorname{In}_{0.7} \mathrm{Ga}_{0.3} \mathrm{As} /$ $\mathrm{GaAs}_{0.35} \mathrm{Sb}_{0.65}$ heterojunction. It was reported that a fixed positive charge of $6 \times 10^{12} \mathrm{~cm}^{-2}$ changed the band alignment from staggered to broken. However, HR-HAADF-STEM analysis shows no visible defects in our diodes (Fig. 5), thus we do not expect fixed charge to affect the measured $\mathrm{E}_{\mathrm{g}, \mathrm{eff}}$.

In conclusion, simulations and experiments of heterojunction Esaki diodes at cryogenic temperature demonstrate a characteristic exponentially increasing BTBT current. It allows us to determine a lower limit $\mathrm{E}_{\mathrm{g}, \mathrm{eff}}>0.21 \mathrm{eV}$ for the $\mathrm{n}+\mathrm{In}_{0.53} \mathrm{Ga}_{0.47} \mathrm{As} / \mathrm{pGaAs}_{0.5} \mathrm{Sb}_{0.5}$ heterojunction using a method that requires knowledge of the dopant concentrations and degeneracies $\xi_{n, p}$ but not the bandgaps and tunnel rates. The exponential current also allows us to determine that the intermixing region at the junction is $<1 \mathrm{~nm}$, which is verified by HR-HAADF-STEM analysis. Other applications include the analysis of fixed charge at the heterojunction and further understanding of dopant-BGN and its impact on TFET.

Q. Smets and D. Verreck gratefully acknowledge the support of IWT-Vlaanderen. This work was supported by imec's industrial affiliation program.

${ }^{1}$ B. R. Bennett, R. Magno, J. B. Boos, W. Kruppa, and M. G. Ancona, "Antimonide-based compound semiconductors for electronic devices: A review," Solid-State Electron. 49, 1875 (2005).

${ }^{2}$ H. Lu and A. Seabaugh, IEEE J. Electron Devices Soc. 2, 44 (2014).

${ }^{3}$ I. Vurgaftman, J. R. Meyer, and L. R. Ram-Mohan, J. Appl. Phys. 89, 5815 (2001).

${ }^{4}$ J. Klem, S. Kurtz, and A. Datye, "Growth and properties of GaAsSb/ InGaAs superlattices on InP,” J. Cryst. Growth 111, 628 (1991).
${ }^{5}$ Y. Zhu, N. Jain, S. Vijayaraghavan, D. K. Mohata, S. Datta, D. Lubyshev, J. M. Fastenau, A. K. Liu, N. Monsegue, and M. K. Hudait, J. Appl. Phys. 112, 094312 (2012).

${ }^{6}$ Q. Smets, A. S. Verhulst, S. E. Kazzi, A. Mocuta, and M. M. Heyns, in Device Research Conference, 2015.

${ }^{7}$ D. Mohata, S. Mookerjea, A. Agrawal, Y. Li, T. Mayer, V. Narayanan, A. Liu, D. Loubychev, J. Fastenau, and S. Datta, Appl. Phys. Express 4, 024105 (2011).

${ }^{8}$ B. Romanczyk, P. Thomas, D. Pawlik, S. L. Rommel, W.-Y. Loh, M. H. Wong, K. Majumdar, W.-E. Wang, and P. D. Kirsch, Appl. Phys. Lett. 102, 213504 (2013).

${ }^{9}$ V. Siklitsky, see http://www.ioffe.ru/SVA/NSM/Semicond/.

${ }^{10}$ T. Yu, J. T. Teherani, D. A. Antoniadis, and J. L. Hoyt, IEEE Electron Device Lett. 34, 1503 (2013).

${ }^{11}$ B. Rajamohanan, R. Pandey, V. Chobpattana, C. Vaz, D. Gundlach, K. P. Cheung, J. Suehle, S. Stemmer, and S. Datta, IEEE Electron Device Lett. 36(1), 20-22 (2015).

${ }^{12}$ D. Mohata, B. Rajamohanan, T. Mayer, M. Hudait, J. Fastenau, D. Lubyshev, A. W. K. Liu, and S. Datta, IEEE Electron Device Lett. 33, 1568 (2012).

${ }^{13}$ R. Bijesh, H. Liu, H. Madan, D. Mohata, W. Li, N. V. Nguyen, D. Gundlach, C. A. Richter, J. Maier, K. Wang, T. Clarke, J. M. Fastenau, D. Loubychev, W. K. Liu, V. Narayanan, and S. Datta, IEEE IEDM 7, 28.2.1-28.2.4 (2013).

${ }^{14}$ Synopsys, Sentaurus Device J-2014.09.

${ }^{15}$ D. Verreck, M. Van de Put, B. Sorée, A. S. Verhulst, W. Magnus, W. G. Vandenberghe, N. Collaert, A. Thean, and G. Groeseneken, J. Appl. Phys. 115, 053706 (2014).

${ }^{16}$ S. M. Sze, Physics of Semiconductor Devices, 2nd ed. (Wiley, New York, 1981), p. 521.

${ }^{17}$ M. Van de Put, in Eurocon (2013), pp. 2134-2139.

${ }^{18} \mathrm{~A}$. Ajoy, in 15th International Workshop on Computational Electronics, IWCE 2012 (2012), pp. 2-5.

${ }^{19}$ E. O. Kane, J. Appl. Phys. 32, 83 (1961).

${ }^{20}$ S. El Kazzi, Q. Smets, M. Ezzedini, R. Rooyackers, A. Verhulst, B. Douhard, H. Bender, N. Collaert, C. Merckling, M. Heyns, and A. Thean, J. Cryst. Growth 424, 62 (2015).

${ }^{21}$ Q. Smets, D. Verreck, A. S. Verhulst, R. Rooyackers, C. Merckling, M. Van De Put, E. Simoen, W. Vandervorst, N. Collaert, V. Y. Thean, B. Sorée, G. Groeseneken, and M. M. Heyns, J. Appl. Phys. 115, 184503 (2014).

${ }^{22}$ V. A. Altschul, A. Fraenkel, and E. Finkman, J. Appl. Phys. 71, 4382 (1992).

${ }^{23}$ E. Zielinski, H. Schweizer, K. Streubel, H. Eisele, and G. Weimann, J. Appl. Phys. 59, 2196 (1986).

${ }^{24}$ R. Lukic-Zrnic, B. P. Gorman, R. J. Cottier, T. D. Golding, and A. G. Norman, J. Appl. Phys. 92, 6939 (2002).

${ }^{25}$ W.-S. Cho, M. Luisier, D. Mohata, S. Datta, D. Pawlik, S. L. Rommel, and G. Klimeck, Appl. Phys. Lett. 100, 063504 (2012).

${ }^{26}$ S. Jain and D. Roulston, Solid-State Electron. 34, 453 (1991). 